\title{
Technical Issues Behind Molecular Monitoring in Chronic Myeloid Leukemia
}

\author{
Elia Mattarucchi ${ }^{1} \cdot$ Francesco Pallotti $^{2,3} \cdot$ Rosario Casalone $^{2}$
}

Published online: 9 April 2015

(C) Springer International Publishing Switzerland 2015

Clinical papers frequently lack in-depth descriptions of analytical methods, triggering possible doubts regarding their conclusions. Through this short communication, we would like to stimulate a debate on the monitoring of chronic myeloid leukemia, a disorder that requires frequent laboratory analysis by RNA reverse transcription and realtime quantitative PCR (RQ-PCR). This is a challenging procedure influenced by a number of factors that are difficult to control $[1,2]$, and troubled by the need to use reference materials to standardize results against the socalled international scale (IS) [3]. The residual disease is evaluated through the amount of $B C R-A B L 1$ transcript, and a patient's response is reported in terms of IS logarithmic reductions, up to the possible condition of apparent undetectable disease [2]. Actually, the outcome of RQ-PCR represents only an estimation of the leukemic clone based on the assumed proportionality between chimeric RNA and leukemic cells. However, it is not clear if this proportionality is still valid at very high response levels, and negative results can be interpreted in a number of ways, e.g., the true absence of leukemic cells, the presence of leukemic cells that do not transcribe chimeric RNA [4], or measurements below the detection limit. Really, an accurate determination of the detection limit is not feasible since specimen

Elia Mattarucchi

elia.mattarucchi@alice.it

1 Department of Experimental and Clinical Medicine, Università dell'Insubria, via Dunant 5, 21100 Varese, Italy

2 Medical Genetics Unit, Ospedale di Circolo e Fondazione Macchi, Varese, Italy

3 Department of Surgical and Morphological Science, Università dell'Insubria, Varese, Italy handling, RNA extraction and retro-transcription are critical pre-analytical steps (due to in vitro RNA instability), and it is practically impossible to characterize the whole process. Even positive (but barely detectable) results are difficult to interpret because of the intrinsic variability of gene expression: patients with few leukemic cells can give significantly different results, depending on small variations in the mutual transcription levels of $B C R-A B L 1$ and the reference gene used as a normalizer (usually $A B L 1$, $B C R$, or $G U S B$ [1]). As a consequence, a clear definition of molecular response is still under elaboration, though the potential for drug discontinuation makes this subject a pressing issue [2]. A survey conducted by the College of American Pathologists pointed out that diverse laboratories testing the same sample obtained different results [1].

Pilot methods based on DNA analysis have also been introduced. These methods require the sequence of the $B C R-A B L 1$ junction for each patient, but have the advantage, of relying on a direct and univocal relationship between cell number and breakpoints (i.e., similar to cytogenetic, but with a higher sensitivity); thus an algorithm can be used to calculate the actual percentage of leukemic cells without the need for standards and reference materials [5]. However, the need to retrieve the breakpoint of each patient affects the routine application of this practice. Recent studies [6] also argue that chronic myeloid leukemia patients (even those with undetectable levels of chimeric RNA) maintain evidence of the $B C R-A B L 1$ DNA, implying its limitations as a prognostic marker. The procedure used to prove this claim consisted of a nested PCR on genomic DNA and a high number of replicates to enhance the chance of detecting the target sequence. This method is frequently used [7,8], but is prone to false positive results, and a thorough technical discussion would 
be necessary. In analytical chemistry, limit of detection/ limit of quantification (LOD/LOQ) and accuracy are distinct subjects [9]. In general, increasing replicates ameliorate the accuracy, but if the single result is below the $\mathrm{LOD} / \mathrm{LOQ}$, the outcome is undetectable/impossible to measure, and repeating the test has no effects. Thus, the approach to lower the LOD/LOQ by increasing the number of replicates is scientifically flawed. These limits could be lowered only by improving the PCR sensitivity or increasing the amount of template of the single reaction. For instance, assuming a PCR sensitivity up to the single breakpoint sequence, the LOD in 50 ng DNA would be $\sim 0.0001 \%$ (1 leukemic cell/8800 cells, considering $5.7 \mathrm{pg} \mathrm{DNA} /$ cell). This limit could be lowered to $0.00001 \%$ analyzing $500 \mathrm{ng}$ DNA (if no inhibition occurs), but not analyzing $10 \times 50 \mathrm{ng}$ samples. Additionally, if replicate results are spanning the LOD (i.e., partially positive and negative), the outcome is uncertain and should be rejected. The real values are higher than the theoretical limits discussed above, and should be experimentally established in order to set acceptance criteria ahead of any clinical interpretation.

In conclusion, molecular monitoring by RNA analysis is the recommended procedure for chronic myeloid leukemia, but clinicians should be aware of the factors that affect this practice. The use of DNA measurements requires even more critical scrutiny. An in-depth understanding of the laboratory methods is necessary for the correct reading of the results, in particular, if the outcome of the residual disease monitoring is used as a prognostic indication for therapy modulation or possible drug discontinuation. We hope that a critical discussion about the abovementioned technical issues may be of value in the management of chronic myeloid leukemia patients.

Acknowledgments The authors have no competing interests. The commentary was written in the framework of the institutional work of the Insubria University and no specific grant was received.

\section{References}

1. Zhen C, Wang YL. Molecular monitoring of chronic myeloid leukemia: international standardization of BCR-ABL1 quantitation. J Mol Diagn. 2013;15:556-64.

2. Cross NCP, White HE, Muller MC, Saglio G, Hochhaus A. Standardized definitions of molecular response in chronic myeloid leukemia. Leukemia. 2012;26:2172-5.

3. Hughes T, Deininger M, Hochhaus A, Branford S, Radich J, Kaeda $\mathrm{J}$, Baccarani M, Cortes J, Cross NC, Druker BJ, Gabert J, Grimwade D, Hehlmann R, Kamel-Reid S, Lipton JH, Longtine J, Martinelli G, Saglio G, Soverini S, Stock W, Goldman JM. Monitoring CML patients responding to treatment with tyrosine kinase inhibitors: review and recommendations for harmonizing current methodology for detecting BCR-ABL transcripts and kinase domain mutations and for expressing results. Blood. 2006;108:28-37.

4. Pellicano F, Mukherjee L, Holyoake TL. Cancer cells escape from oncogene addiction: understanding the mechanisms behind treatment failure for more effective targeting. Stem Cells. 2014;32:1373-9.

5. Mattarucchi E, Spinelli O, Rambaldi A, Pasquali F, Lo Curto F, Campiotti L, Porta G. Molecular monitoring of residual disease in chronic myeloid leukemia by genomic DNA compared with conventional mRNA analysis. J Mol Diagn. 2009;11:482-7.

6. Ross DM, Branford S, Seymour JF, Schwarer AP, Arthur C, Bartley PA, Slader C, Field C, Dang P, Filshie RJ, Mills AK, Grigg AP, Melo JV, Hughes TP. Patients with chronic myeloid leukemia who maintain a complete molecular response after stopping imatinib treatment have evidence of persistent leukemia by DNA PCR. Leukemia. 2010;24:1719-24.

7. Ross DM, Branford S, Seymour JF, Schwarer AP, Arthur C, Yeung DT, Dang P, Goyne JM, Slader C, Filshie RJ, Mills AK, Melo JV, White DL, Grigg AP, Hughes TP. Safety and efficacy of imatinib cessation for CML patients with stable undetectable minimal residual disease: results from the TWISTER study. Blood. 2013;122:515-22.

8. Bartley PA, Ross DM, Latham S, Martin-Harris MH, Budgen B, Wilczek V, Branford S, Hughes TP, Morley AA. Sensitive detection and quantification of minimal residual disease in chronic myeloid leukaemia using nested quantitative PCR for BCR-ABL DNA. Int J Lab Hematol. 2010;32:222-8.

9. Armbruster DA, Pry T. Limit of blank, limit of detection and limit of quantitation. Clin Biochem Rev. 2008;29:S49-52. 